\title{
In trans $\mathbf{T}$ cell tolerance exacerbates experimental allergic encephalomyelitis by interfering with protective antibody responses
}

\author{
Jason A. Cascio ${ }^{\mathrm{a}}$, Marie-Therese Khairallah ${ }^{\mathrm{a}}$, Xiaoxiao Wan ${ }^{\mathrm{a}}$, Weirong Chen ${ }^{\mathrm{a}}$, Linda M. \\ Rowland $^{\mathrm{a}}$, Mermagya Dhakal ${ }^{\mathrm{a}}$, Mindy M. Miller ${ }^{\mathrm{a}}$, and Habib Zaghouania,b,c, ${ }^{*}$ \\ aDepartment of Molecular Microbiology and Immunology, University of Missouri School of \\ Medicine, M616 Medical Sciences Building, Columbia, MO 65212 USA \\ bDepartment of Child Health, University of Missouri School of Medicine, M616 Medical Sciences \\ Building, Columbia, MO 65212 USA \\ 'Department of Neurology, University of Missouri School of Medicine, M616 Medical Sciences \\ Building, Columbia, MO 65212 USA
}

\begin{abstract}
$\mathrm{F}_{1}(\mathrm{SJL} / \mathrm{J}$ x C57BL/6) mice with MOG35-55-induced EAE recover from disease when treated with Ig-MOG carrying MOG35-55 peptide. However, Ig-PLP1, carrying PLP139-151, induced reduction of anti-MOG antibodies and exacerbated EAE. Herein, we show that Ig-PLP1 specifically reduces the frequency of B cells producing protective IgG2a/b anti-MOG antibodies. Surprisingly, these cells were marginal zone (MZ), rather than follicular (FO) or newly formed (NF), B cells and transfer of MZ B cells into sick mice nullified disease exacerbation by Ig-PLP1 in a complement dependent manner. These findings reveal a potential self-limiting regulatory mechanism involving auto-antibodies in MOG EAE.
\end{abstract}

\section{Keywords}

Autoimmunity; EAE; B cells; Anti-MOG antibodies; T cell tolerance

\section{Introduction}

\begin{abstract}
In previous studies we have shown that Ig-PLP1, expressing the $\mathrm{H}-2^{\mathrm{s}}$ restricted proteolipid protein (PLP) peptide 139-151, is able to suppress relapses of PLP1-induced EAE (Legge et al., 2000). Aggregation of the chimera further enhances its tolerogenic function and modulates both the initial severe phase of EAE as well as the subsequent relapses (Legge, Min, 2000). Moreover, aggregated (agg) Ig-PLP1 displayed effective bystander suppression and was able to counter disease induced by central nervous system (CNS) homogenate, which involves diverse T specificities (Legge, Min, 2000). Similarly, Ig-MOG, carrying the
\end{abstract}

*Corresponding author at: Department of Molecular Microbiology and Immunology, The University of Missouri School of Medicine. M616 Medical Sciences Bldg., Columbia, MO 65212. Phone: (573) 884-0659, Fax: (573) 882-4287, zaghouanih@ health.missouri.edu (H.Zaghouani). 
$\mathrm{H}-2^{\mathrm{b}}$ restricted myelin oligodendrocyte glycoprotein (MOG) 35-55 peptide, is able to inhibit MOG-induced EAE (Legge et al., 2002). In addition agg Ig-MOG also displays bystander suppression and ameliorates CNS homogenate-induced EAE (Legge, Gregg, 2002). Given this efficacy we tested the chimera for suppression of disease under circumstances relevant to human polymorphism. Indeed, when (SJL/J x C57BL/6) $\mathrm{F}_{1}$ mice, which carry both parental haplotypes, were induced for EAE with PLP1 peptide, both agg IgPLP1 and IgMOG were able to modulate the disease (Bell et al., 2008). This suggested that Ig-PLP1 sustains cis while Ig-MOG supports in trans tolerance to modulate PLP-1 specific T cells (Bell, Divekar, 2008). However, when disease was induced with MOG peptide, cis tolerance was effective and Ig-MOG was able to modulate EAE, but in trans tolerance was nonfunctional and agg Ig-PLP1 exacerbated MOG EAE (Bell, Divekar, 2008). Initial investigation of the mechanism underlying exacerbation of MOG EAE by treatment with agg Ig-PLP1 indicated that the regimen induced IL-5 production by PLP1-specific T cells, which led to inhibition of the production of anti-MOG antibodies by B cells (Bell, Divekar, 2008). Herein, we show that exacerbation of EAE is due to a specific suppression of protective anti-MOG antibodies that otherwise contribute to disease resolution. Given that the protective anti-MOG antibodies were of the $\operatorname{IgG} 2 \mathrm{a} / \mathrm{b}$ isotype, and Ig switching requires interaction of B and T cells, we envisioned that FO B cells would be the subset producing the protective anti-MOG antibodies. The results, however, indicated that marginal zone (MZ), but not follicular (FO) or newly formed (NF), IgG2a/b $\mathrm{b}^{+} \mathrm{B}$ cells produce protective anti-MOG antibody and, upon transfer these MZ B cells sustain disease resolution in a complement dependent manner. These findings reveal a potential self-limiting regulatory mechanism of MOG EAE in $\mathrm{F}_{1}$ mice in which MOG specific $\mathrm{B}$ cells produce autoantibodies that contribute to disease resolution rather than pathogenesis, which may have important implications for the design of antigen specific therapies.

\section{Materials and methods}

\subsection{Animals}

$\mathrm{SJL} / \mathrm{J}\left(\mathrm{H}-2^{\mathrm{s}}\right)$ and C57BL/6 $\left(\mathrm{H}-2^{\mathrm{b}}\right)$ mice were purchased from The Jackson Laboratory. $\mathrm{F}_{1}$ (SJL/J x C57BL/6) mice were generated by breeding male SJL/J to female C57BL/6 mice. All mice were bred and maintained in our animal care facility for the duration of the experiments. All experimental procedures were performed according to the guidelines of the University of Missouri animal care and use committee.

\subsection{Antigens}

2.2.1. Peptide-Myelin oligodendrocyte glycoprotein (MOG) peptide (MEVGWYRSPFSRVVHLYRNGK) encompassing aa residues 35-55 of MOG was purchased from EZBiolab (Westfield, IN).

2.2.2. Ig chimeras-Ig-PLP1 (Legge et al., 1997) incorporates proteolipid protein aa residues 139-151 (PLP1) inserted within the $\mathrm{H}$ chain complementarity determining region 3. $\mathrm{Ig}-\mathrm{W}$ is the parental IgG2b, $\kappa$ molecule not encompassing any myelin or other peptide. All chimera transfectants are grown up in large-scale cultures and purified from culture supernatant on affinity chromatography columns made of rat anti-mouse $\kappa$-chain coupled to 
CNBr-activated Sepharose 4B (Amersham Biosciences). Aggregation of Ig chimeras was done using 50\%-saturated $\left(\mathrm{NH}_{4}\right)_{2} \mathrm{SO}_{4}$ as described previously (Legge, Min, 2000).

\subsection{Induction and scoring of EAE}

Induction of active EAE has been previously described (Divekar et al., 2011). Briefly,

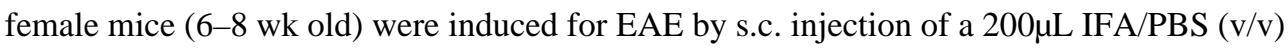

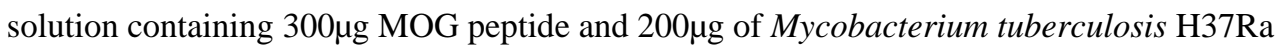
(Difco) in the footpads and at the base of the limbs. Six hours later, mice were given i.v. 500ng purified Bordetella pertussis toxin (List Biological Laboratories). A second injection of B. pertussis toxin was given after $48 \mathrm{~h}$. The mice were scored daily for clinical signs of EAE as follows: 0 , no clinical signs; 1 , loss of tail tone; 2 , hind limb weakness; 3 , hind limb paralysis; 4 , forelimb paralysis; and 5, moribund or death.

\subsection{Agg Ig-chimera treatment of EAE}

Mice were treated three times, 4 days apart with $300 \mu \mathrm{g}$ of agg Ig chimeras at the first observation of clinical signs as described previously (Bell, Divekar, 2008) (Legge, Min, 2000). Typically, the treatments were given on days 10,14 , and18 post -disease induction.

\subsection{Detection of MOG-specific Abs by ELISA}

For detection of anti-MOG Abs in the serum, ELISA was used according to the following protocol. Fifty microliters of $0.1 \mathrm{M}$ bicarbonate buffer containing $7 \mu \mathrm{g} / \mathrm{mL}$ MOG peptide was coated into 96-well plates and incubated overnight at $4^{\circ} \mathrm{C}$. The plates were then washed and saturated with PBS-3\% BSA. Subsequently, serial dilutions of serum were added and incubated overnight at $4{ }^{\circ} \mathrm{C}$. Total anti-MOG, IgG2a, and IgG2b antibodies were detected using the Southern Biotechnology Associates clonotyping kit according to the manufacturer's instructions.

\subsection{Flow cytometry}

Antibodies were purchased from BD Biosciences or Ebiosciences. Antibodies used were phycoerythrin (PE)-conjugated CD21 (7E9), fluorescein isothiocyanate (FITC)-conjugated IgG2a/b (R2-40), allophycocyanin (APC)-conjugated B220 (RA3-6B2), and PE-Cy7conjugated CD23 (B3B4). Cells were collected using a Beckman Coulter CyAn (Brea, CA) and data were analyzed using FlowJo version 8.8.6 (Tree Star).

\subsection{Sorting}

Cells were sorted on a Beckman Coulter MoFlo (Brea, CA). For IgG2a/b $\mathrm{b}^{+} \mathrm{B}$ cells, splenic cells were harvested from $\mathrm{F}_{1}$ mice and stained with anti-B220 and anti-IgG2a/b antibodies. Cells identified as B220 ${ }^{+}$were sorted on the basis of IgG2a/b expression. For MZ and FO B cells, splenic cells were stained with anti-B220, anti-CD21, and anti-CD23 antibodies. Cells identified as $\mathrm{B} 220^{+}$were sorted on the basis of $\mathrm{CD} 21$ and $\mathrm{CD} 23$. Cell purity was routinely checked, and only sorts with a purity of $\geq 95 \%$ were used in this study. 


\subsection{Depletion of complement}

Complement was depleted in $\mathrm{F}_{1}$ mice with MOG EAE on day 20 post-disease induction by

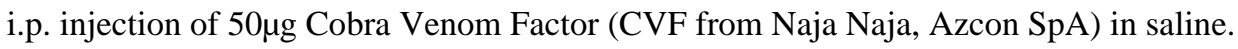

\subsection{Statistical analysis}

Data were analyzed using unpaired two-tailed Student's t tests, or Mann-Whitney test where indicated, using Prism software v4.0c (Graphpad).

\section{Results}

\subsection{Agg Ig-PLP1 diminishes IgG2a/b+B cells and exacerbates MOG EAE}

To gain insight on how agg Ig-PLP1 interferes with the humoral anti-MOG response, we sought to determine whether the treatment diminishes the frequency of responding $\mathrm{B}$ cells. To this end, $\mathrm{F}_{1}(\mathrm{SJL} / \mathrm{Jx}$ C57BL/6 ) mice were induced for EAE with MOG peptide, treated with either agg Ig-PLP1 or the control agg Ig-W, and anti-MOG antibodies and B cells were measured. As can be seen in Figure 1A, treatment with agg Ig-PLP1 resulted in a pronounced exacerbation of MOG EAE relative to agg Ig-W treated mice $(\mathrm{p}<0.001$, Mann Whitney test), which is consistent with our previous findings (Bell, Divekar, 2008). Indeed, while the mean maximal disease score (MMS) was similar in both groups $(2.1 \pm 0.3$ versus $2.3 \pm 0.3$ ) the mice treated with agg Ig-W recovered from EAE by day $42.3 \pm 1.7$, whereas those recipient of agg Ig-PLP1 failed to recover from disease for the duration of the monitoring period (> 60 days). Furthermore, while anti-MOG antibodies were readily detectable following treatment with agg Ig-W, agg Ig-PLP1 diminished total anti-MOG antibodies significantly, with a specific loss of $\operatorname{IgG} 2 \mathrm{a}$ and $\mathrm{IgG} 2 \mathrm{~b}$ isotypes (Fig. 1B). We then envisioned that the isotype-specific reduction of anti-MOG antibodies could be due to diminished antibody secretion by the $\mathrm{B}$ cells or to a decrease in the frequency of antibodyproducing $\mathrm{B}$ cells. To test this premise, $\mathrm{F}_{1}$ mice with ongoing EAE were treated with agg IgPLP1 and the frequency of B cells expressing membrane-bound $\mathrm{IgG} 2 \mathrm{a} / \mathrm{IgG} 2 \mathrm{~b}$ isotype were analyzed. The results indicate that mice recipient of agg Ig-PLP1 displayed a diminished frequency of B220 $\mathrm{IgG} 2 \mathrm{a} / \mathrm{b}^{+}$splenic B cells compared to mice recipient of agg Ig-W (Fig. 1C). Indeed, while $6.1 \%$ of B cells were IgG2a/b-positive in the Ig-W-treated mice, only $1.9 \%$ had the IgG2a/b isotype in the agg Ig-PLP1-treated mice. This decrease is consistent because compiled results from 3 experiments show a similar decrease from $6.13 \pm 0.20 \%$ in the agg IgW mice to $2.04 \pm 0.18 \%$ in the agg Ig-PLP1 groups (Fig. 1D). Overall, these results suggest that the diminished anti-MOG IgG2a and IgG2b antibody response in agg IgPLP1 treated mice is due to diminished $\mathrm{B} 220^{+} \mathrm{IgG} 2 \mathrm{a} / \mathrm{b}^{+} \mathrm{B}$ cells in the spleen.

\subsection{Anti-MOG serum induces transient protection against Ig-PLP1 exacerbation}

Given that disease exacerbation by agg Ig-PLP1 correlates with diminished anti-MOG antibodies, and that restoration of this antibody response by neutralization of IL-5 alleviates disease exacerbation (Bell, Divekar, 2008), it is logical to envision that these antibodies contribute protective, rather than pathogenic, functions. To test this hypothesis, we began by determining the titer of anti-MOG antibodies at the indicated time points throughout the course of disease (Fig. 2A). Remarkably, high anti-MOG antibody titers were observed throughout the 60 day disease monitoring period (Fig. 2B). In addition, both IgG2a (Fig. 2C) 
and $\mathrm{IgG} 2 \mathrm{~b}$ (Fig. 2D) anti-MOG antibody titers remained high relative to pre-immune serum. Of note, there was a slight progressive decrease in these titers which correlated with disease resolution, which normally occurs around day 42 post disease induction (Fig. 2A). Given the correlation between the anti-MOG antibody titer and disease resolution, it is possible that the antibodies play a protective role against Ig-PLP1-mediated disease exacerbation. To test this premise, $\mathrm{F}_{1}$ mice induced for MOG EAE were treated with agg Ig-PLP1 to induce disease exacerbation and the animals were given anti-MOG serum from $\mathrm{F}_{1}$ donors with ongoing EAE. Interestingly, mice recipient of anti-MOG serum displayed a decrease in disease severity that did not occur in animals given normal serum from $\mathrm{F}_{1}$ mice (Fig. 2E). The remission, however, was temporary, but additional injections of MOG serum reestablished remission. Although transient, these remission episodes were significant as the MMS went down from $2.1 \pm 0.2$ to $1.33 \pm 0.1$ during remission 1 and from $2.0 \pm 0.2$ to $1.1 \pm$ 0.1 in remission 2 for mice given anti-MOG serum relative to those recipients of normal serum (Fig. 2F). Overall, these results suggest that anti-MOG antibodies contribute protective function against Ig-PLP1-mediatedexacerbation.

\subsection{IgG2a/b+ B cells restore anti-MOG antibodies and nullify agg Ig-PLP1-mediated disease exacerbation}

Given that anti-MOG sera sustained transient rather than long lasting protection against disease exacerbation, it is possible that a consistent supply of the protective antibody is required to counteract persistent disease severity, especially since anti-MOG $\operatorname{IgG} 2 \mathrm{a} / \mathrm{b}^{+} \mathrm{B}$ cells are diminished during treatment with agg Ig-PLP1. Therefore, we sought to enrich with $\operatorname{IgG} 2 \mathrm{a} / \mathrm{b}^{+} \mathrm{B}$ cells and test for long-lasting remission from disease exacerbation. To test this premise, $F_{1}$ mice induced for EAE with MOG peptide and treated with agg Ig-PLP1 were adoptively transferred with $\mathrm{B} 220^{+} \mathrm{IgG} 2 \mathrm{a} / \mathrm{b}^{+} \mathrm{B}$ cells sorted from the spleens of $\mathrm{F}_{1}$ donors with ongoing MOG EAE, and the hosts were monitored for prevention of disease exacerbation. As indicated in Figure 3A, the B cell transfer nullified disease exacerbation and the animals had a pattern of disease similar to the control animals treated with Ig-W ( $\mathrm{p}=$ 0.71 , Mann Whitney test). In contrast, depletion of $\operatorname{IgG} 2 \mathrm{a} / \mathrm{b}^{+}$cells (non- $\gamma 2 \mathrm{a} / \mathrm{b}$ ) abrogated the ability to protect against disease exacerbation (Fig. 3B) ( $p<0.001$, Mann Whitney test). Similarly, B cells from $F_{1}$ mice that were without EAE could not counter Ig-PLP1-mediated disease exacerbation (Fig. 3C) ( $p<0.001$, Mann Whitney test). Taken together, these results indicate that $\mathrm{IgG} 2 \mathrm{a} / \mathrm{b}^{+}$B cells contribute protective functions to MOG EAE and prevent agg Ig-PLP1 mediated disease exacerbation. To determine whether the protection driven by the $\mathrm{IgG} 2 \mathrm{a} / \mathrm{b}^{+} \mathrm{B}$ cells is due to production of anti-MOG antibodies, we measured the titers of these antibodies in the serum of mice recipient of $\operatorname{IgG} 2 \mathrm{a} / \mathrm{b}^{+} \mathrm{B}$ cell transfer and compared them to titers from hosts that received pre-immune B cell transfer. The results show that the $\mathrm{IgG} 2 \mathrm{a} / \mathrm{b}^{+} \mathrm{B}$ cell transfer restored a higher anti-MOG antibody titer relative to the control animals receiving pre-immune B cells (Fig. 3D). In fact, the increase was significant for total anti-MOG antibody as well as the $\mathrm{IgG} 2 \mathrm{a}$ and $\mathrm{IgG} 2 \mathrm{~b}$ isotypes. Overall, $\mathrm{IgG} 2 \mathrm{a} / \mathrm{b}^{+} \mathrm{B}$ cells restore serum anti-MOG antibodies and contribute protective functions against agg Ig-PLP1mediated exacerbation of MOG EAE. 


\subsection{Marginal zone, but not other, IgG2a/b+ B cells protect against Ig-PLP1-mediated exacerbation of EAE}

Splenic B cells comprise many subsets including marginal zone $(\mathrm{MZ})\left(\mathrm{CD} 2 \mathrm{1}^{\mathrm{hi}} \mathrm{CD} 23^{\mathrm{lo}}\right)$, follicular (FO) $\left(\mathrm{CD} 21^{\mathrm{lo}} \mathrm{CD} 23^{\mathrm{hi}}\right)$, and newly formed (NF) $\left(\mathrm{CD} 21^{-} \mathrm{CD} 23^{-}\right)$subsets (Attanavanich and Kearney, 2004). Since anti-MOG antibodies belong mostly to the T celldependent IgG2a/b isotype, one would predict that FO B cells would be involved in the production of the protective antibodies. To test this premise, we began by analyzing the phenotype of the splenic $\mathrm{B}$ cells producing the protective anti-MOG antibodies. Accordingly, when the splenic $\mathrm{B} 220^{+}$cells from the donor $\mathrm{F}_{1}$ mice with EAE were stained for $\mathrm{CD} 21$ and $\mathrm{CD} 23$, there were MZ, NF, and FO B cells as would be observed in normal mice (Fig. 4A). When the populations were analyzed for surface $\mathrm{IgG} 2 \mathrm{a} / \mathrm{b}$ isotype expression, it became evident but surprising that a substantial frequency of $\operatorname{IgG} 2 \mathrm{a} / \mathrm{b}^{+} \mathrm{B}$ cells displayed a surface phenotype consistent with MZ B cells (Fig. 4A). A much lower frequency of cells had FO or NF phenotype. The MZ and FO cells were then sorted and tested for protection against Ig-PLP1-mediated exacerbation of EAE. Intriguingly, mice recipient of $\mathrm{B} 220^{+} \mathrm{CD} 21^{\text {hi }} \mathrm{CD} 23^{\text {lo }}$ (MZ B cells) were protected against disease exacerbation and maintained a pattern of paralysis similar to mice treated with agg Ig-W, which do not undergo exacerbation (Fig. 2B) ( $\mathrm{p}=0.48$, Mann-Whitney test). In contrast, mice recipient of $\mathrm{B} 220^{+} \mathrm{CD} 21^{\mathrm{lo}} \mathrm{CD} 23^{\mathrm{hi}}$ (FO B cells) had a disease course that was significantly exacerbated compared to agg Ig-W treated mice ( $\mathrm{p}<0.001$, Mann-Whitney test). These results indicate that the protective $\mathrm{IgG} 2 \mathrm{a} / \mathrm{b}^{+} \mathrm{B}$ cells that expand in $\mathrm{F}_{1}$ mice with MOG EAE originate from the marginal zone of the spleen.

\subsection{Protection against disease exacerbation by $\lg G 2 a / b^{+} B$ cells is dependent on serum complement proteins}

The complement system has previously been demonstrated to play an important role in oligodendrocyte damage and demyelination during MS and EAE (Nataf et al., 2000, Terenyi et al., 2009). However, other reports have suggested that the complement system can also provide protective function to oligodendrocytes, primarily be preventing apoptosis(Cudrici et al., 2006a, Cudrici et al., 2006b, Niculescu et al., 2004, Soane et al., 1999). Given that the classical pathway of complement can be triggered by IgG antibodies binding to target cells, and that anti-MOG IgG2a/b antibodies are protective against Ig-PLP1 exacerbation, we reasoned that the complement system may play a role in the $\operatorname{IgG} 2 \mathrm{a} / \mathrm{b}^{+} \mathrm{B}$ cell mediated protection in $\mathrm{F}_{1}$ mice. To test this premise, we sought to determine whether $\operatorname{IgG} 2 \mathrm{a} / \mathrm{b}^{+} \mathrm{B}$ cells could prevent Ig-PLP1-mediated disease exacerbation when the mice were given cobra venom factor, a complement $\mathrm{C} 3 \mathrm{~b}$ analog that depletes $\mathrm{C} 3$ and $\mathrm{C} 5$ from the circulation (Vogel et al., 2004). The results show that complement depletion completely abrogates the protective effect of IgG2a/ $\mathrm{b}^{+}$B cell transfer (Fig. 5). Indeed, while mice recipient of $\mathrm{IgG} 2 \mathrm{a} / \mathrm{b}^{+} \mathrm{B}$ cell transfer alone recovered from disease exacerbation within the monitoring period, those recipient of $\operatorname{IgG} 2 \mathrm{a} / \mathrm{b}^{+} \mathrm{B}$ cells that were depleted of complement displayed pronounced disease exacerbation similar to agg Ig-PLP1- treated animals. These findings indicate that $\mathrm{IgG} 2 \mathrm{a} / \mathrm{b}^{+} \mathrm{B}$ cells and their ant $\mathrm{i}-\mathrm{MOG}$ auto-antibodies likely mediate their protective function through activation of the complement system. 


\section{Discussion}

In previous studies, we have shown that Ig-MOG and Ig-PLP1 are effective against EAE induced by MOG and PLP1 peptide, respectively (Cascio et al., 2013, Divekar, Haymaker, 2011, Legge et al., 2001, Legge, Gregg, 2002, Legge, Min, 2000). Also, both chimeras were able to display bystander suppression and modulate CNS homogenate-induced EAE which involves multiple epitopes and diverse $\mathrm{T}$ cell specificities. We then assayed the chimeras for suppression of EAE in an $\mathrm{F}_{1}(\mathrm{SJL} / \mathrm{J}$ x C57BL/6) mouse model where the MHC haplotype would display greater allelic polymorphism similar to humans (Bell, Divekar, 2008). Under these circumstances, while Ig-MOG was able to modulate both MOG- and PLP1-induced EAE in the $\mathrm{F}_{1}$ mice, Ig-PLP1 was only able to overcome PLP1-induced EAE and exacerbated rather than reduced the severity of MOG driven disease (Bell, Divekar, 2008). Interestingly, the mechanism underlying disease exacerbation involved the production of IL-5 by PLP1-specific CD4 T cells, which led to interference with the production of antiMOG antibodies, which, despite being implicated in the pathogenesis of MS and EAE (Kap et al., 2010, Kennel De March et al., 2003, Pollinger et al., 2009, Tsunoda et al., 2005), seemed to assist in disease resolution in this case (Bell, Divekar, 2008). Although the MOG35-55-induced EAE model has long been thought to not involve autoantibodies, several recent reports have observed MOG-specific antibodies in humans (O'Connor et al., 2005) and C57BL/6 mice (Lalive, 2008, Lalive et al., 2011), as well as (SJL/J x C57BL/6) $\mathrm{F}_{1}$ mice (Skundric et al., 2003, Zhang et al., 2004), but their significance and pathogenic potential remain poorly understood. Previous reports with the $\mathrm{F}_{1}$ mouse model, in particular, uncovered high levels of anti-MOG antibodies during MOG-induced EAE, but this did not correlate with enhanced disease severity relative to mice in which the anti-MOG antibody response was absent (Zhang, Yu, 2004), supporting the premise that these antibodies may not contribute pathogenic function. Furthermore, it has been shown that pathogenic antiMOG antibodies are directed against conformational epitopes, while those recognizing linear epitopes do not contribute to demyelination (Khalil et al., 2006, Menge et al., 2011, O'Connor et al., 2007, von Budingen et al., 2004, Zhou et al., 2006). Herein, since the antiMOG antibodies are induced and detected by linear MOG35-55 peptide, it stands to reason that the humoral anti-MOG response in $\mathrm{F}_{1}$ mice may not be pathogenic. Moreover, we demonstrate that the anti-MOG antibodies are indeed protective against Ig-PLP1-mediated exacerbation of EAE in $\mathrm{F}_{1}$ mice as serum collected from mice with ongoing EAE can nullify the otherwise heightened disease severity observed upon Ig-PLP1 treatment. More specifically, the protection against disease was associated with the $\operatorname{IgG} 2 \mathrm{a}$ and $\operatorname{IgG} 2 \mathrm{~b}$ isotypes, and $\mathrm{B}$ cells expressing surface $\mathrm{IgG} 2 \mathrm{a} / \mathrm{b}$ drive long-lasting suppression of disease exacerbation, which leads to effective resolution. Since IgG2a/b expression results from isotype switching which requires interaction with $\mathrm{T}$ follicular helper $\left(\mathrm{T}_{\mathrm{FH}}\right)$ cells (Reinhardt et al., 2009), one would envision that FO rather than MZ or NF B cells are responsible for the production of anti-MOG antibodies. To our surprise, however, the protective IgG2a/b $\mathrm{b}^{+} \mathrm{B}$ cells were MZ B cells, which usually play a role in T cell independent responses (Martin et al., 2001). Recent evidence, however, has implicated MZ B cells in T cell dependent responses as well (Chappell et al., 2012, Song and Cerny, 2003), and indicated that these cells are indeed capable of capturing, processing, and presenting soluble protein antigens to $\mathrm{T}$ cells even more efficiently than their FO B cell counterparts (Attanavanich and Kearney, 
2004). This attribute, along with the ability of MZ B cells to rapidly differentiate into longlived antibody secreting plasma cells (Cerutti et al., 2013), may uniquely position the MZ B cell population to provide the protective IgG2a and IgG2b anti-MOG antibodies observed in $\mathrm{F}_{1}$ MOG EAE. Importantly, the MZ B cell compartment does not represent an inherently protective population of cells, as only the $\mathrm{IgG} 2 \mathrm{a} / \mathrm{b}^{+} \mathrm{B}$ cells are capable of conferring protection against Ig-PLP1.

In addition, given the proficiency of the IgG isotype for activating the classical complement cascade (Carroll, 2004), we reasoned that the protective function of IgG2a and IgG2b antiMOG antibodies may involve the complement system. Indeed, depletion of complement completely nullified the protective effect of IgG2a $/ \mathrm{b}^{+} \mathrm{B}$ cells against Ig-PLP1-mediated disease exacerbation. Thus, it is likely that the anti-MOG antibodies activate a protective, rather than pathogenic, complement cascade, which has been previously reported to inhibit oliogodendrocyte apoptosis (Cudrici, Niculescu, 2006b, Niculescu, Weerth, 2004, Soane, Rus, 1999, Weerth et al., 2003) and promote re-myelination during EAE resolution (Weerth, Rus, 2003). Therefore, the loss of IgG2a/ $\mathrm{b}^{+} \mathrm{B}$ cells and their antibodies following treatment with Ig-PLP1 would inhibit these resolution promoting mechanisms and result in disease exacerbation. Overall, this study demonstrates a previously unappreciated aspect of a myelin-reactive autoantibody response. Namely, induction of MOG EAE in polymorphic $\mathrm{F}_{1}$ mice induces an $\mathrm{IgG} 2 \mathrm{a}$ and $\mathrm{IgG} 2 \mathrm{~b}$ anti-MOG antibody response with protective, rather than pathogenic, properties. In trans treatment with agg Ig-PLP1 diminishes both $\operatorname{IgG} 2 \mathrm{a} / \mathrm{b}^{+} \mathrm{B}$ cells and their antibodies, resulting in pronounced disease exacerbation. This exacerbation could be alleviated temporarily by supplementing mice with anti-MOG serum or permanently via transfer of $\operatorname{IgG} 2 \mathrm{a} / \mathrm{b}^{+} \mathrm{B}$ cells from the spleens of MOG-immunized $\mathrm{F}_{1}$ donor mice. Intriguingly, this IgG2a/ $\mathrm{b}^{+} \mathrm{B}$ cell population seems to originate from the marginal zone of the spleen and is dependent on complement to exert its protective function. Of note, transfer of anti-MOG serum or IgG2a/ $/ \mathrm{b}^{+}$B cells did not cure or reverse EAE, but rather simply prevented agg Ig-PLP1 from making the disease worse. Thus, IgG2a/ $\mathrm{b}^{+} \mathrm{B}$ cells and their antibodies likely represent a previously unappreciated mechanism to limit myelin damage and sustain EAE resolution. While this study raises new questions as to the mechanisms underlying this ability, it highlights the need to understand the complex interactions that occur under polymorphic disease conditions in order to better devise antigen-specific therapies against autoimmunity.

\section{Acknowledgments}

This work was supported by grants RO1 NS057194 (to H.Z.) from the National Institutes of Health, and by the J. Lavenia Edwards endowment (to HZ).

\section{References}

Attanavanich K, Kearney JF. Marginal zone, but not follicular B cells, are potent activators of naive CD4 T cells. J Immunol. 2004; 172:803-11. [PubMed: 14707050]

Bell JJ, Divekar RD, Ellis JS, Cascio JA, Haymaker CL, Jain R, et al. In trans T cell tolerance diminishes autoantibody responses and exacerbates experimental allergic encephalomyelitis. $\mathbf{J}$ Immunol. 2008; 180:1508-16. [PubMed: 18209046]

Carroll MC. The complement system in regulation of adaptive immunity. Nature immunology. 2004; 5:981-6. [PubMed: 15454921] 
Cascio JA, Haymaker CL, Divekar RD, Zaghouani S, Khairallah MT, Wan X, et al. Antigen-Specific Effector CD4 T Lymphocytes School Lamina Propria Dendritic Cells To Transfer Innate Tolerance. J Immunol. 2013

Cerutti A, Cols M, Puga I. Marginal zone B cells: virtues of innate-like antibody-producing lymphocytes. Nature reviews Immunology. 2013; 13:118-32.

Chappell CP, Draves KE, Giltiay NV, Clark EA. Extrafollicular B cell activation by marginal zone dendritic cells drives $\mathrm{T}$ cell-dependent antibody responses. The Journal of experimental medicine. 2012; 209:1825-40. [PubMed: 22966002]

Cudrici C, Niculescu F, Jensen T, Zafranskaia E, Fosbrink M, Rus V, et al. C5b-9 terminal complex protects oligodendrocytes from apoptotic cell death by inhibiting caspase- 8 processing and upregulating FLIP. J Immunol. 2006a; 176:3173-80. [PubMed: 16493077]

Cudrici C, Niculescu T, Niculescu F, Shin ML, Rus H. Oligodendrocyte cell death in pathogenesis of multiple sclerosis: Protection of oligodendrocytes from apoptosis by complement. Journal of rehabilitation research and development. 2006b; 43:123-32. [PubMed: 16847778]

Divekar RD, Haymaker CL, Cascio JA, Guloglu BF, Ellis JS, Tartar DM, et al. T cell dynamics during induction of tolerance and suppression of experimental allergic encephalomyelitis. J Immunol. 2011; 187:3979-86. [PubMed: 21911603]

Kap YS, van Driel N, Blezer E, Parren PW, Bleeker WK, Laman JD, et al. Late B cell depletion with a human anti-human CD20 IgG1kappa monoclonal antibody halts the development of experimental autoimmune encephalomyelitis in marmosets. J Immunol. 2010; 185:3990-4003. [PubMed: 20739677]

Kennel De March A, De Bouwerie M, Kolopp-Sarda MN, Faure GC, Bene MC, Bernard CC. Antimyelin oligodendrocyte glycoprotein B-cell responses in multiple sclerosis. Journal of neuroimmunology. 2003; 135:117-25. [PubMed: 12576231]

Khalil M, Reindl M, Lutterotti A, Kuenz B, Ehling R, Gneiss C, et al. Epitope specificity of serum antibodies directed against the extracellular domain of myelin oligodendrocyte glycoprotein: Influence of relapses and immunomodulatory treatments. Journal of neuroimmunology. 2006; 174:147-56. [PubMed: 16516980]

Lalive PH. Autoantibodies in inflammatory demyelinating diseases of the central nervous system. Swiss medical weekly. 2008; 138:692-707. [PubMed: 18951202]

Lalive PH, Molnarfi N, Benkhoucha M, Weber MS, Santiago-Raber ML. Antibody response in MOG(35-55) induced EAE. Journal of neuroimmunology. 2011; 240-241:28-33.

Legge KL, Bell JJ, Li L, Gregg R, Caprio JC, Zaghouani H. Multi-modal antigen specific therapy for autoimmunity. International reviews of immunology. 2001; 20:593-611. [PubMed: 11890614]

Legge KL, Gregg RK, Maldonado-Lopez R, Li L, Caprio JC, Moser M, et al. On the role of dendritic cells in peripheral $\mathrm{T}$ cell tolerance and modulation of autoimmunity. The Journal of experimental medicine. 2002; 196:217-27. [PubMed: 12119346]

Legge KL, Min B, Bell JJ, Caprio JC, Li L, Gregg RK, et al. Coupling of peripheral tolerance to endogenous interleukin 10 promotes effective modulation of myelin-activated $\mathrm{T}$ cells and ameliorates experimental allergic encephalomyelitis. The Journal of experimental medicine. 2000; 191:2039-52. [PubMed: 10859329]

Legge KL, Min B, Potter NT, Zaghouani H. Presentation of a T cell receptor antagonist peptide by immunoglobulins ablates activation of $\mathrm{T}$ cells by a synthetic peptide or proteins requiring endocytic processing. The Journal of experimental medicine. 1997; 185:1043-53. [PubMed: 9091578]

Martin F, Oliver AM, Kearney JF. Marginal zone and B1 B cells unite in the early response against Tindependent blood-borne particulate antigens. Immunity. 2001; 14:617-29. [PubMed: 11371363]

Menge T, Lalive PH, von Budingen HC, Genain CP. Conformational epitopes of myelin oligodendrocyte glycoprotein are targets of potentially pathogenic antibody responses in multiple sclerosis. Journal of neuroinflammation. 2011; 8:161. [PubMed: 22093619]

Nataf S, Carroll SL, Wetsel RA, Szalai AJ, Barnum SR. Attenuation of experimental autoimmune demyelination in complement-deficient mice. J Immunol. 2000; 165:5867-73. [PubMed: 11067947] 
Niculescu T, Weerth S, Niculescu F, Cudrici C, Rus V, Raine CS, et al. Effects of complement C5 on apoptosis in experimental autoimmune encephalomyelitis. J Immunol. 2004; 172:5702-6. [PubMed: 15100315]

O'Connor KC, Appel H, Bregoli L, Call ME, Catz I, Chan JA, et al. Antibodies from inflamed central nervous system tissue recognize myelin oligodendrocyte glycoprotein. J Immunol. 2005; 175:1974-82. [PubMed: 16034142]

O'Connor KC, McLaughlin KA, De Jager PL, Chitnis T, Bettelli E, Xu C, et al. Self-antigen tetramers discriminate between myelin autoantibodies to native or denatured protein. Nature medicine. 2007; 13:211-7.

Pollinger B, Krishnamoorthy G, Berer K, Lassmann H, Bosl MR, Dunn R, et al. Spontaneous relapsing-remitting EAE in the SJL/J mouse: MOG-reactive transgenic T cells recruit endogenous MOG-specific B cells. The Journal of experimental medicine. 2009; 206:1303-16. [PubMed: 19487416]

Reinhardt RL, Liang HE, Locksley RM. Cytokine-secreting follicular T cells shape the antibody repertoire. Nature immunology. 2009; 10:385-93. [PubMed: 19252490]

Skundric DS, Zakarian V, Dai R, Lisak RP, Tse HY, James J. Distinct immune regulation of the response to $\mathrm{H}-2 \mathrm{~b}$ restricted epitope of MOG causes relapsing-remitting EAE in $\mathrm{H}-2 \mathrm{~b} / \mathrm{s}$ mice. Journal of neuroimmunology. 2003; 136:34-45. [PubMed: 12620641]

Soane L, Rus H, Niculescu F, Shin ML. Inhibition of oligodendrocyte apoptosis by sublytic C5b-9 is associated with enhanced synthesis of bcl-2 and mediated by inhibition of caspase- 3 activation. J Immunol. 1999; 163:6132-8. [PubMed: 10570303]

Song H, Cerny J. Functional heterogeneity of marginal zone B cells revealed by their ability to generate both early antibody-forming cells and germinal centers with hypermutation and memory in response to a T-dependent antigen. The Journal of experimental medicine. 2003; 198:1923-35. [PubMed: 14662910]

Terenyi N, Nagy N, Papp K, Prechl J, Olah I, Erdei A. Transient decomplementation of mice delays onset of experimental autoimmune encephalomyelitis and impairs MOG-specific T cell response and autoantibody production. Molecular immunology. 2009; 47:57-63. [PubMed: 19201476]

Tsunoda I, Kuang LQ, Igenge IZ, Fujinami RS. Converting relapsing remitting to secondary progressive experimental allergic encephalomyelitis (EAE) by ultraviolet B irradiation. Journal of neuroimmunology. 2005; 160:122-34. [PubMed: 15710465]

Vogel CW, Fritzinger DC, Hew BE, Thorne M, Bammert H. Recombinant cobra venom factor. Molecular immunology. 2004; 41:191-9. [PubMed: 15159065]

von Budingen HC, Hauser SL, Ouallet JC, Tanuma N, Menge T, Genain CP. Frontline: Epitope recognition on the myelin/oligodendrocyte glycoprotein differentially influences disease phenotype and antibody effector functions in autoimmune demyelination. European journal of immunology. 2004; 34:2072-83. [PubMed: 15259004]

Weerth SH, Rus H, Shin ML, Raine CS. Complement C5 in experimental autoimmune encephalomyelitis (EAE) facilitates remyelination and prevents gliosis. The American journal of pathology. 2003; 163:1069-80. [PubMed: 12937147]

Zhang GX, Yu S, Gran B, Li J, Calida D, Ventura E, et al. T cell and antibody responses in remittingrelapsing experimental autoimmune encephalomyelitis in (C57BL/6 x SJL) F1 mice. Journal of neuroimmunology. 2004; 148:1-10. [PubMed: 14975581]

Zhou D, Srivastava R, Nessler S, Grummel V, Sommer N, Bruck W, et al. Identification of a pathogenic antibody response to native myelin oligodendrocyte glycoprotein in multiple sclerosis. Proceedings of the National Academy of Sciences of the United States of America. 2006; 103:19057-62. [PubMed: 17142321] 
A

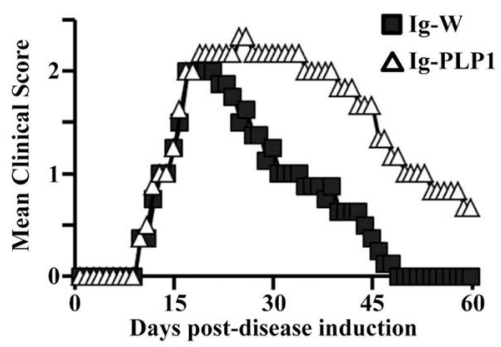

C

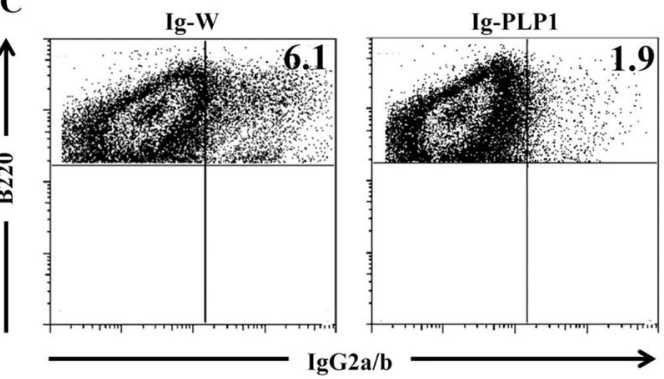

B

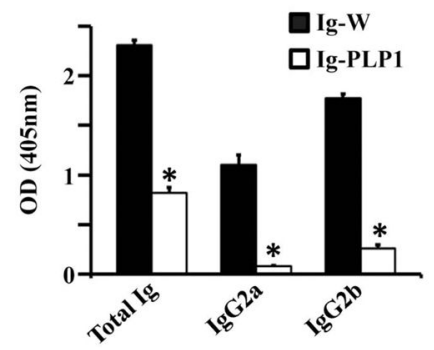

D

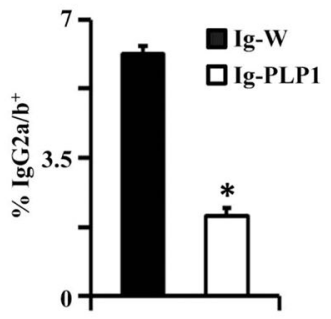

Figure 1. Agg Ig-PLP1 diminishes IgG2a/ $/ \mathrm{b}^{+} \mathrm{B}$ cells and exacerbates MOG EAE

(A) Groups of $\left(\mathrm{SJL} / \mathrm{J} \times \mathrm{C}\right.$ 7 BL/6) $\mathrm{F}_{1}$ mice were induced for EAE with MOG peptide and at

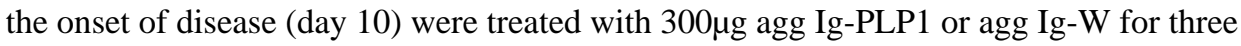
times at 4 day intervals. The mice were monitored daily for signs of paralysis and scored according to the grading scale described in Materials and Methods. Data is representative of 3 independent experiments with 3-4 mice per group. (B) The mice were also bled via tail veins 2 days after the last Ig-chimera injection and total, IgG2a, and IgG2b MOG Abs were measured by ELISA as described in Materials and Methods. * indicates $\mathrm{p}<0.001$. (C-D) Mice induced for MOG EAE and treated as in (A) were sacrificed 2 days after the last Igchimera injection and their splenic cells were stained with anti-B220 and anti-IgG2a/b antibodies and analyzed by flow cytometry. $\mathbf{C}$ shows representative flow cytometry plots of B $220^{+} \mathrm{IgG} 2 \mathrm{a} / \mathrm{b}^{+}$cells from the indicated treatment groups. Dshows compiled results from 5 independent experiments of the percentage of $\mathrm{IgG} 2 \mathrm{a} / \mathrm{b}^{+}$cells among the total B220 ${ }^{+}$population. * indicates $\mathrm{p}<0.001$. 
A

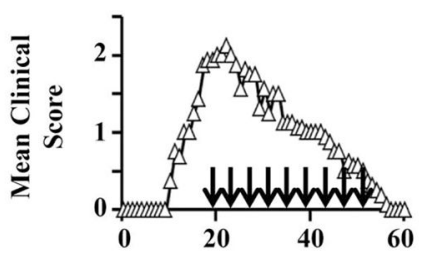

C

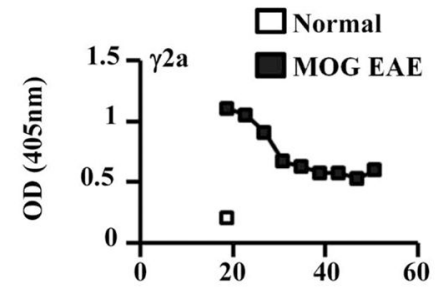

B

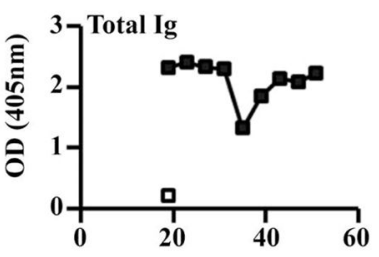

D

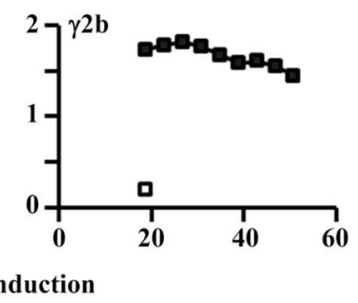

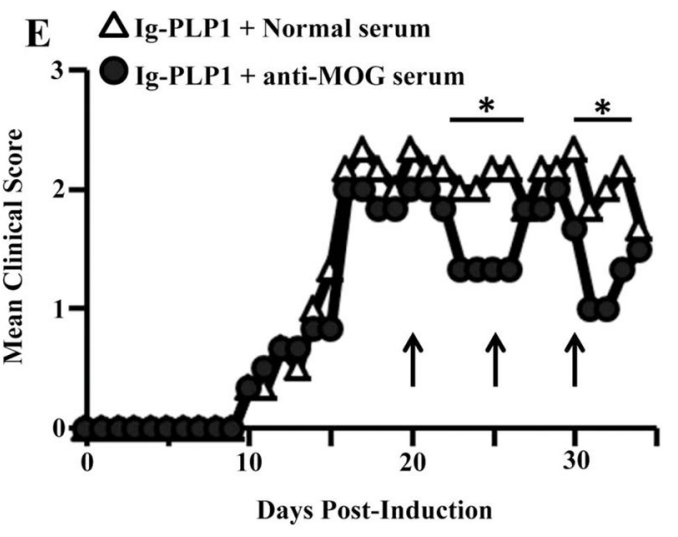

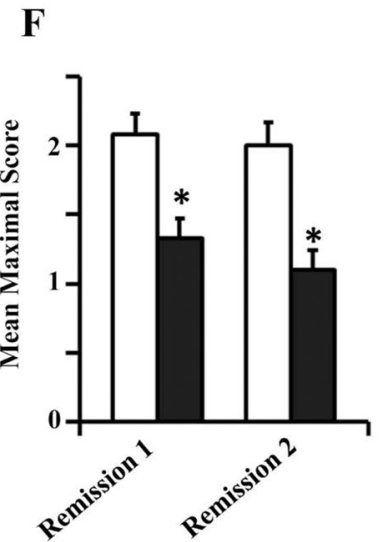

Figure 2. Anti-MOG serum confers protection against Ig-PLP1 exacerbation

(A) Groups of $\mathrm{F}_{1}(\mathrm{SJL} / \mathrm{J}$ x C57BL/6) mice induced for EAE with MOG peptide were monitored daily for clinical symptoms and bled via tail veins once every 4 days beginning at day 19 as indicated by arrows. (B-D) The serum from each bleeding was evaluated for Total, IgG2a, and IgG2b MOG Abs by ELISA as described in Materials and Methods. Serum from non-immunized (Normal) mice was included for control purposes. (E) Groups of $F_{1}$ mice were induced for EAE with MOG peptide and at the onset of disease (day 10) were treated with $300 \mu \mathrm{g}$ agg Ig-PLP1 for three times at 4 day intervals. Two days later, the mice were injected i.v. with $50 \mu \mathrm{L}$ normal serum or anti-MOG serum collected from the day 19 time point shown in (A). An additional injection of anti-MOG serum was given at days 25 and 30 (arrows). The mice continued EAE monitoring as described above. Data is representative of 4 independent experiments with 3-4 mice per group. * indicates $p<0.01$ by Mann-Whitney test. (F) shows the mean maximal EAE scores observed during the two remissions phases compiled from 3 independent experiments. * indicates $\mathrm{p}<0.002$ by student's t test. 

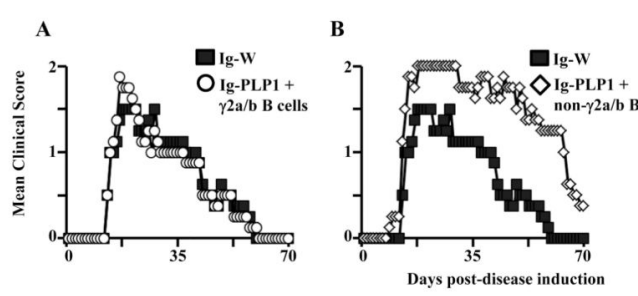

C

D
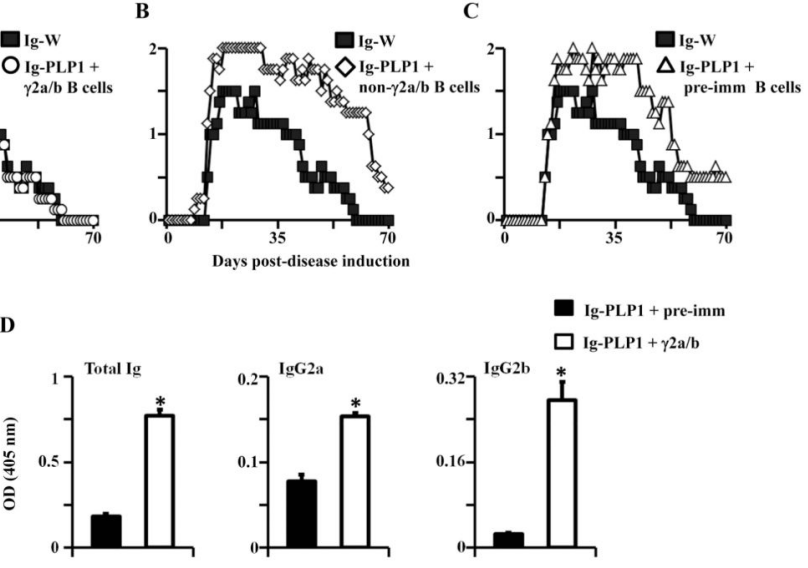

Figure 3. IgG2a/ $/ \mathrm{b}^{+} \mathrm{B}$ cells restore anti-MOG antibodies and nullify agg Ig-PLP1-mediated disease exacerbation

(A-C) Groups of $\mathrm{F}_{1}(\mathrm{SJL} / \mathrm{J}$ x C57BL/6) mice were induced for EAE with MOG peptide and

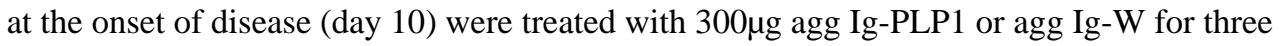
times at 4 day intervals. The mice were monitored daily for signs of paralysis and scored according to the grading scale described in Materials and Methods. Two days after the last Ig-chimera injection, Ig-PLP1 treated mice were injected with $3 \times 10^{5} \mathrm{~B} 220^{+} \operatorname{IgG} 2 \mathrm{a} / \mathrm{b}^{+}(\mathbf{A})$ or $\operatorname{IgG} 2 \mathrm{a} / \mathrm{b}^{-}$(B) B cells sorted from the spleens of donor $\mathrm{F}_{1}$ mice with ongoing MOG EAE. A third Ig-PLP1 treated group received B220 ${ }^{+}$B cells sorted from the spleens of nonimmunized donor mice (C). Data is representative of 3 independent experiments with 3-4 mice per group. In (D), Ig-PLP1 treated mice were bled via the tail vein 14 days after receiving either pre-immune or IgG2a/ $\mathrm{b}^{+} \mathrm{B}$ cells and total, IgG2a, and IgG2b MOG Abs were measured by ELISA as described in Materials and Methods. * indicates $\mathrm{p}<0.002$. 
A
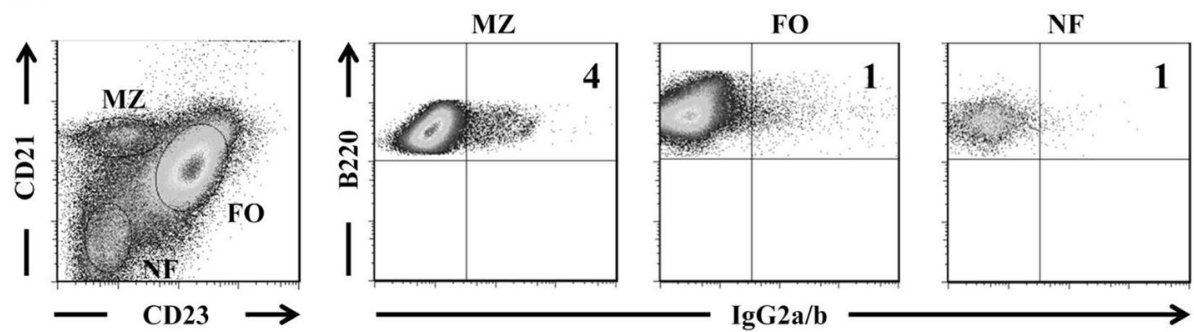

B

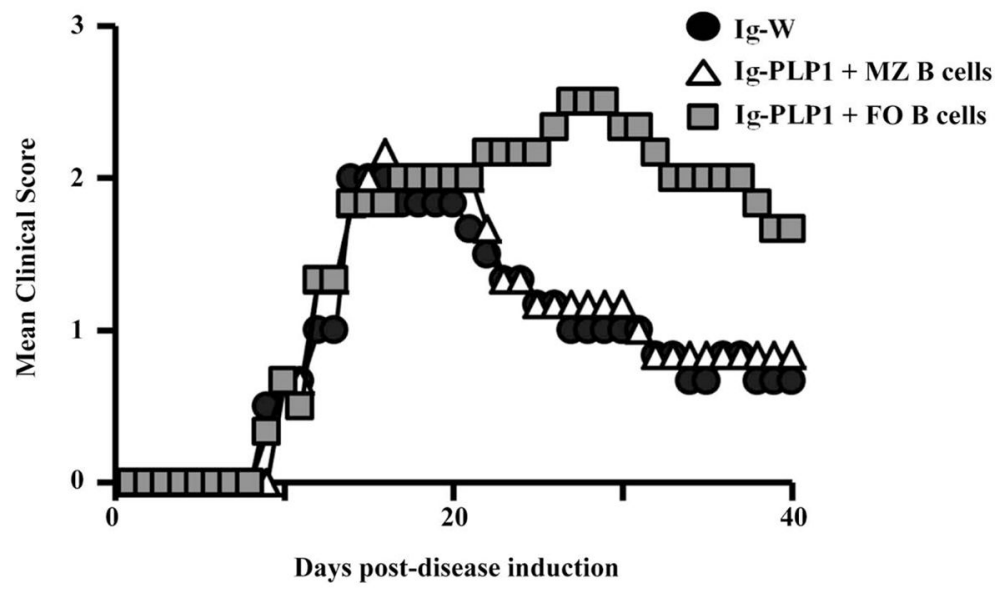

Figure 4. Marginal zone, but not follicular, IgG2a/ $\mathrm{b}^{+} \mathrm{B}$ cells protect against Ig-PLP1-mediated exacerbation of EAE

In (A), groups of $F_{1}$ mice were induced for EAE with $M O G$ peptide. At 15 days postimmunization, mice were sacrificed and their splenic cells were stained with anti-B220, anti$\operatorname{IgG} 2 \mathrm{a} / \mathrm{b}$, anti-CD21, and anti-CD23 antibodies and analyzed by flow cytometry. The representative plots depict $\mathrm{CD} 21$ and $\mathrm{CD} 23$ expression on gated B220 ${ }^{+}$cells (left panel), as well as $\mathrm{IgG} 2 \mathrm{a} / \mathrm{b}$ expression on gated $\mathrm{B} 220^{+} \mathrm{CD} 21^{\mathrm{hi}} \mathrm{CD} 23^{\mathrm{lo}}(\mathrm{MZ}), \mathrm{B} 220^{+} \mathrm{CD} 21^{\mathrm{lo}} \mathrm{CD} 23^{\mathrm{hi}}$ (FO), and $\mathrm{B} 220^{+} \mathrm{CD} 21^{-} \mathrm{CD} 23^{-}$(NF) populations. In (B), $\mathrm{F}_{1}$ mice induced for EAE with MOG peptide were treated with $300 \mu \mathrm{g}$ agg Ig-PLP1 or agg Ig-W. Two days after the last Igchimera injection, Ig-PLP1 treated mice were injected with $3 \times 10^{5} \mathrm{~B} 220^{+} \mathrm{CD} 21^{\text {hi }} \mathrm{CD} 23^{\text {lo }}$ (MZ B cells) or B220 $0^{+} \mathrm{CD} 21^{\mathrm{lo}} \mathrm{CD} 23^{\text {hi }}$ (FO B cells) cells sorted from the spleens of donor $\mathrm{F}_{1}$ mice with ongoing MOG EAE. Mice were scored daily for clinical symptoms for the duration of the monitoring period. Data is representative of three independent experiments with 3-4 mice per group. 


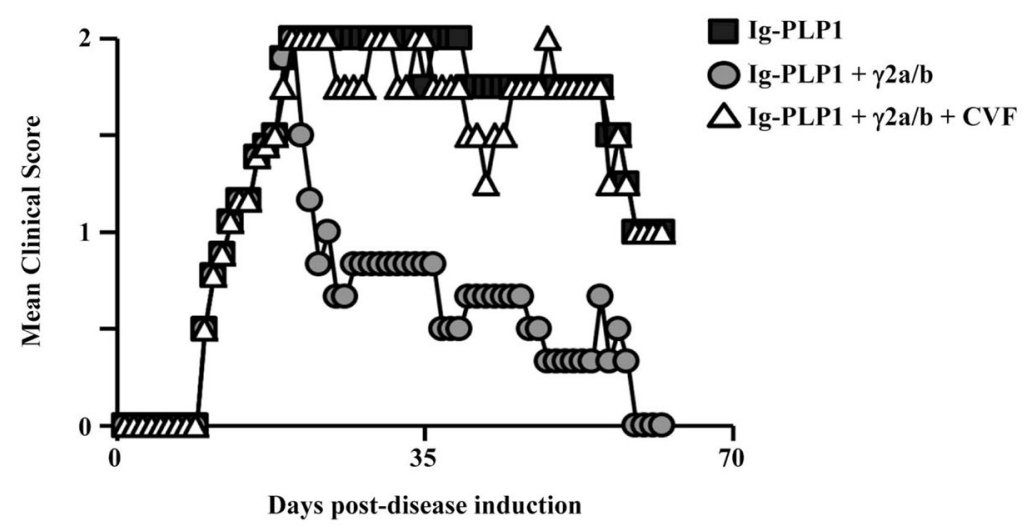

Figure 5. Protection against disease exacerbation by $\operatorname{IgG2a} / \mathrm{b}^{+} \mathrm{B}$ cells is dependent on serum complement proteins

Groups of $F_{1}$ mice were induced for EAE with MOG peptide and treated with $300 \mu \mathrm{g}$ agg Ig-PLP1 for three times at 4 day intervals. Two days later, one group was injected i.v. with 3 x $10^{5} \mathrm{~B} 220^{+} \mathrm{IgG} 2 \mathrm{a} / \mathrm{b}^{+} \mathrm{B}$ cells sorted from the spleens of donor $\mathrm{F}_{1}$ mice with ongoing MOG EAE (circles). A second group received IgG2a $/ \mathrm{b}^{+} \mathrm{B}$ cells along with $50 \mu \mathrm{g}$ cobra venom factor to deplete complement (triangles). A third group received no B cell transfer or cobra venom factor (squares). Mice were scored daily for clinical symptoms for the indicated period of time. Data is representative of three independent experiments. 